\title{
Fixed Drug Eruption Due to A Cerumenolytic Ear Drop; Hydrogen Peroxide and Boric Acid: A Case Report
}

\author{
Akif İşlek $^{1 *}$ and Engin Karaaslan ${ }^{2}$ \\ ${ }^{1}$ Nusaybin State Hospital, Otolaryngology-Head \& Neck Surgery Clinic, Mardin, Turkey \\ ${ }^{2}$ Nusaybin State Hospital, Dermatology and Venereology, Mardin, Turkey
}

*Corresponding author: Akif İşlek, Nusaybin State Hospital, Otolaryngology-Head \&

Neck Surgery Clinic, Mardin, Turkey.

Received Date: October 24, 2020

Published Date: November 03, 2020

\begin{abstract}
Treatment of earwax often involves the use of a wax softening agent (cerumenolytic) with or without antimicrobial agents to easily removing. Cerumenolytic agents used to remove and soften earwax areoil-based treatments, water-based treatments. Fixed drug eruption (FDE) is a welldefined, circular, hyperpigmented plaque that usually occurs on the trunk, hands mucosal surfaces, after a systemical application of drugs. In this report, a case with FDE developed after a cerumenolytic agent (hydrogen peroxide and boric acid in water). A definitive diagnosis was made with skin punch biopsy and FDE was treated with oral levocetirizine and topical mometasone.
\end{abstract}

\section{Introduction}

Cerumen production is a normal and protective process for the external ear canal (EAC), but impact of cerumen causes symptoms such as hearing loss, itching, pain, tinnitus [1]. Cerumen impaction is defined as an accumulation of cerumen in the external ear [2]. Ear cleaning with cotton buds, particularly when the EAC is wet might be one of the important causes of cerumen impaction. Impacted cerumen is composed of abnormal exfoliated keratinocytes and correlated with microbial-induced neutrophilmediated inflammation and increases recurrent mold infection [3]. Treatment of earwax often involves use of a wax softening agent (cerumenolytic) with or without antimicrobial agents to disperse the cerumen and reduce the need syringing in incompatible population or facilitate syringing. Cerumenolytic agents used to remove and soften earwax areoil-based treatments (triethanolamine polypeptide, almond oil, benzocaine, chlorobutanol), water-based treatments (docusate sodium, carbamide peroxide, phenazone, choline salicylate, urea peroxide, potassium carbonate, glycerol, hydrogen peroxide and boric acid) [4]. Fixed drug eruption (FDE) is a well-defined, circular, hyper pigmenting plaque that usually occurs on the genitals, lips, trunk, and hands and the diagnosis can be confirmed by histopathologic examination of a small punch biopsy specimen [5]. In this report, a case with FDE developed after a cerumenolytic agent (hydrogen peroxide and boric acid in water) for used in clinical routine is presented.

\section{Case Report}

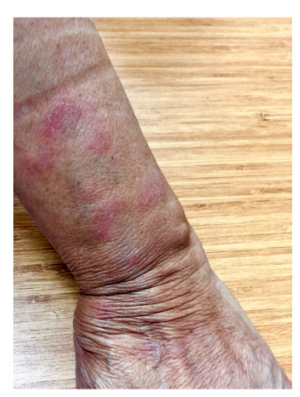

Figure 1: Erythematous macules and dusky red or violaceous edematous plaques with desquamation on the left arm and hand. 
A 67-year-old female patient was diagnosed with earwax in both ears in the otorhinolaryngology examination, and control visit planned 10 days later to remove impacted serumen with prescribing cerumenolytic (hydrogen peroxide 2\% and boric acid $2 \%$ in water). Patients admitted to hospital three day later and complaints of diffuse lesions and itching (Figure 1). Patients has no history of use any other drugs or chemicals. A laboratory examination showed that the white blood cell (WBC) count was 9.7 x 109, the neutrophil count was $7.1 \times 109$ (73.4\%), the lymphocyte count was $1.9 \times 109$ (20.2\%), the eosinophil count the was $0.48 \times$ 109 (5.1\%), C-reactive protein (CRP) level was $1.2 \mathrm{U} / \mathrm{mL}$, and the erythrocyte sedimentation rate (ESR) was $7 \mathrm{~mm} / \mathrm{h}$. The ear wax removed.

The tympanic membrane was intact bilaterally and the EEC was natural in the physical examination. Pure tone averages were normal. Oral mucosal lesions were not detected. Patinet was consulted to Dermatologist. Pruritic, well-circumscribed, erythematous macules and dusky red or violaceous edematous plaques $(14-26 \mathrm{~mm}$ in diameter) scattered on the trunk and extremities were inspected with the dermatological examination. A skin punch biopsy was planned. Antihistamine agent (Levocetirizine $10 \mathrm{mg}$, bid) and topical hydrocortisone (mometasone $0.1 \%$ ) was prescribed for the patient. Ear drop treatment was stopped. After 6 days with antihistamine treatment, the lesions regressed. Skin punch biopsy demonstrated perivascular infiltration of mononuclear cells with dyskeratotic cells in the epidermis and intercellular edema. Also, eosinophils and marked vascular wall thickening detected in the dermis. After the histopathological examination a definitive diagnosis was made as FDE.

\section{Discussion}

Commonly drugs cause FDE includes antimicrobials, nonsteroidal anti-inflammatory drugs, analgesics, and anticonvulsants, and occurs after a minimum of $1 \mathrm{~h}$ later than oral intake. Although, chlorhexidine mouthwash-induced fixed drug eruption was well defined and discussed in recent literature [6]. FDE due to epidermal application of the drugs was not detected in the literature review. Hydrogen peroxide $2 \%$ and boric acid $2 \%$ in water is an effective agent as a wax softening agent (cerumenolytic) and usually applies epidermally. The main toxic effect of exposure to hydrogen peroxide is irritation at the site of contact or whitening of the skin with diluted solutions. Application of boric acid may cause redness, mild burning due to irritation in the application site. The carbamide peroxide demonstrated a significantly lower effect for the cerumen sample's disintegration according to the product containing sodium bicarbonate, glycerin, and other buffering agents [7]. Generally, the adverse events occur dependent on the application due to local irritation such as pruritus, otalgia, and edema in EEC. FDE due to chlorhexidine mouthwash demonstrated in the literature and this drug reaction appeared after usually systemic use of the drugs, so that FDE due to topical application is a very rare disease.

\section{Conclusion}

This case report is a preliminary report for the systemic side effects of cerumenolytic agents. Therefore, the carbamide peroxide compounds can be suggested to be considered as the last agent used to softening agent for impacted cerumen.

\section{Acknowledgement}

None.

\section{Conflict of Interest}

The authors declare that they have no conflict of interest.

\section{References}

1. Michaudet C, Malaty J (2018) Cerumen Impaction: Diagnosis and Management. Am Fam Physician 98(8): 525-529.

2. Schwartz SR, Magit AE, Rosenfeld RM, Bopanna B Ballachanda, Jesse M Hackell, et al. (2017) Clinical Practice Guideline (Update): Earwax (Cerumen Impaction) Otolaryngol Head Neck Surg 156(1_suppl): S1S29.

3. Zhang S, Jin M, Zhou G, Zhang Y (2020) Cerumen impaction was composed of abnormal exfoliation of keratinocytes that was correlated with infection. Am J Otolaryngol 41(2): 102340.

4. Burton MJ, Doree C (2009) Ear drops for the removal of ear wax. Cochrane Database Syst Rev (1): CD004326.

5. Flowers H, Brodell R, Brents M, Wyatt JP (2014) Fixed drug eruptions: presentation, diagnosis, and management. South Med J 107(11): 724727.

6. Moghadam BK, Drisko CL, Gier RE (1991) Chlorhexidine mouthwashinduced fixed drug eruption. Case report and review of the literature. Oral Surg Oral Med Oral Pathol 71(4): 431-434.

7. Fullington D, Song J, Gilles A (2017) Evaluation of the safety and efficacy of a novel product for the removal of impacted human cerumen. BMC Ear Nose Throat Disord 17: 5 . 